assessed by High-resolution computed Tomography (HRCT). Statistical analyses were performed using SPSS 20.0. The $t$-test was employed to compare means of continuous variables, whereas chi-square test was used to compare frequencies. Variables that were significantly associated with ILD using univariate analyses, were included in multivariate logistic regression model. Statistical significance was considered if $\mathbf{p}<\mathbf{0 . 0 5}$.

Results: The majority $(89.2 \%)$ of patients were female. Mean age was $52.6 \pm 12.53$ years and disease duration was $11.2 \pm 9.3$ years. A total of $48(16.7 \%)$ patients were noted to have respiratory symptomatology. Lung involvement was documented in 189 (65.6\%) patients. In each compartment of the lung, abnormal HRCT findings suggestive of ILD were detected in $134(70.8 \%)$ cases, bronchiectasis in $37(19.5 \%)$ and then pleural effusion in 11 (5.8\%) (Table 1).

Table 1. Frequency of subtype's pleuropulmonary involvement detected on HRTC $(n=189)$

\begin{tabular}{lcc}
\hline $\begin{array}{l}\text { Lung abnormal types } \\
\mathrm{N}(\%)\end{array}$ & Lung abnormal & $\mathrm{N}(\%)$ \\
\hline Interstitial lunge disease & Sub-types N (\%) \\
$\mathbf{1 3 4}(\mathbf{7 0 . 8} \%)$ & Usual interstiel pneumonia & $113(59.7 \%)$ \\
& Non-specific interstiel pneumonia & $23(12.1 \%)$ \\
& Cryptogenic organizing pneumonia & $3(1.5 \%)$ \\
Airways respiratory disease & Fcute interstiel pneumonia/diffuse alveolar damage & $0(0 \%)$ \\
$\mathbf{5 0 ( 2 6 . 4 \% )}$ & Fibrosis & $18(9.5 \%)$ \\
& Bronchiectasis & $37(19.5 \%)$ \\
Pleural damage & Follicular bronchiolitis & $10(5.2 \%)$ \\
$\mathbf{2 0}(\mathbf{1 0 . 5} \%)$ & Obliterative Bronchiolitis & $2(1.05 \%)$ \\
& Effusion & $11(5.8 \%)$ \\
& Pleural thickening & $6(3.17)$ \\
& Nodules & $3(1.5 \%)$ \\
\hline
\end{tabular}

In multivariate analysis, ILD was associated with male older age (OR=1.43 95\% IC [1.202-1.952], $p=0.037$ ), advanced age at RA onset (OR=2.17, 95\% IC [1.151-1.874], $p=0.007$ ), extra-articular manifestations (OR=10.8, 95\% IC [5.31212.300], $\boldsymbol{p}<\mathbf{0 . 0 0 1})$, disease activity (OR=2.68, 95\% IC [1.463-1.715], $\boldsymbol{p}<0.001)$ and low methotrexate dose (OR=1.03, 95\% IC [1.003-1.106], $p=0.031)$.

Conclusion: ILD was the most prevalent manifestation of RA lung involvement, it was associated to male gender, older age active and severe RA. References:

[1] Paolo Spagnolo et al. The lung in rheumatoid arthritis. Focus on interstitial lung Disease. Arthritis and Rheumatology. 2018-5, 1-11. Doi: 10.1002/ art.40574.

[2] Ana C. Duate et al. The lung in a cohort of rheumatoid arthritis patients-an overview of different types of involvement ant treatment. Oxford University Press. British Society for Rheumatology.2019-4. Doi:10.1093/rheumatology/ kez177.

Disclosure of Interests: None declared

DOI: 10.1136/annrheumdis-2020-eular.4475

\section{AB0204 \\ A NEW INFLAMMATORY MARKER ASSOCIATED WITH DISEASE ACTIVITY IN PATIENTS WITH RHEUMATOID ARTHRITIS: PLATELET TO ALBUMIN RATIO}

M. Liu ${ }^{1}$, Y. Huang ${ }^{1}$, Z. Huang ${ }^{1}$, Q. Huang ${ }^{1}$, T. Li ${ }^{1} .{ }^{1}$ Guangdong Second Provincial General Hospital, Department of Rheumatology and Immunology, Guangzhou, China

Background: Rheumatoid arthritis (RA) is an inflammatory autoimmune disease characterized by disordered immunity and dysregulated cytokine. Neutrophil to lymphocyte ratio (NLR) and platelet to lymphocyte ratio (PLR) have been defined as inflammatory markers to evaluate disease activity of RA. Recently, platelet to albumin ratio (PAR) was reported as a new prognostic index in patients with cancer. However, similar studies have not been displayed in RA.

Objectives: This study was to explore the role of PAR in RA and its association with disease activity.

Methods: This retrospective study enrolled 136 RA patients and 87 age- and gender-matched healthy controls. Neutrophil, lymphocyte, monocyte, platelet, hemoglobin, albumin, NLR, neutrophil to hemoglobin ratio (NHR), neutrophil to albumin ratio (NAR), monocyte to lymphocyte ratio (MLR), monocyte to hemoglobin ratio(MHR), monocyte to albumin ratio(MAR), PLR, platelet to hemoglobin ratio $(\mathrm{PHR}), \mathrm{PAR}, \mathrm{C}$-reactive protein (CRP), erythrocyte sedimentation rate (ESR) and Disease Activity Score of 28 joints - ESR (DAS28-ESR) were detected. Receiver operation characteristic (ROC) curve was used to discriminate RA patients from healthy individuals. Relationships between PAR and DAS28-ESR as well as other laboratory data were measured by the Spearman's correlations analysis.

Results: RA patients showed higher levels of NLR, NHR, NAR, MLR, MHR, MAR, PLR, PHR PAR and lower levels of albumin than healthy controls. PAR and other inflammatory parameters were also raised along with increased disease activity in RA patients $(P<0.05)$ except NHR $(P=0.098)$. Similarly, albumin was decreased in $R A$ patients as the disease activity increased $(P=0.001)$ ROC showed that area under curve (AUC) of PAR $(0.887,95 \% \mathrm{Cl}: 0.843-0.931)$ was higher than NLR $(0.818,95 \% \mathrm{Cl}: 0.762-0.874), \mathrm{NHR}(0.839,95 \% \mathrm{Cl}: 0.787$ 0.890), NAR(0.829, 95\%Cl: 0.776-0.882), MLR (0.794, 95\%Cl: $0.734-0.854)$ $\operatorname{MHR}(0.817,95 \% \mathrm{Cl}: 0.760-0.874), \operatorname{MAR}(0.814,95 \% \mathrm{Cl}: 0.757-0.872), \operatorname{PLR}(0.832$ 95\% $\%$ : $0.779-0.886), \operatorname{PHR}(0.884,95 \% \mathrm{Cl}: 0.838-0.930)$ and albumin $(0.860$ $95 \% \mathrm{Cl}: 0.813-0.908)$. Besides, PAR was positively correlated with DAS28-ESR ( $=0.429, \mathrm{P}<0.001)$, CRP $(r=0.540, P<0.001)$ and ESR $(r=0.492, P<0.001)$ yielding a highest relevance than other inflammatory indexes.

Conclusion: This study demonstrated that PAR was elevated in RA patients and increased with the disease activity. PAR may be a novel marker to assess the disease activity of RA patients.

References:

[1] Li C, Peng W, Zhang X Y, et al. The preoperative platelet to albumin ratio predicts the prognosis of hepatocellular carcinoma patients without portal hypertension after liver resection[J]. Medicine, 2019, 98:e17920.

Acknowledgments: Science and Technology Project of Haizhu District (No.Hai ke gong shang xin ji 2018-89), Youth Foundation of Guangdong Second Provincial General Hospital (No. YQ2017-009).

Disclosure of Interests: None declared

DOI: 10.1136/annrheumdis-2020-eular.5473

\section{$\mathrm{AB} 0205$ \\ PREDICTORS OF ULTRASOUND DETECTED INFLAMMATORY FINDINGS IN PATIENTS WITH INFLAMMATORY ARTHRALGIA}

K. López Gloria ${ }^{1}$, I. Castrejon ${ }^{2}$, L. Trives Folguera ${ }^{2}$, J. C. Nieto ${ }^{1}$, B. Serrano Benavente $^{2}$, J. Martínez-Barrio ${ }^{1}$, J. Rivera ${ }^{2}$, C. Gonzalez¹ , I. Monteagudo², J. M. Alvaro-Gracia ${ }^{1}$, J. Molina Collada ${ }^{2} .{ }^{1}$ Hospital Universitario Gregorio Marañón, Madrid, Spain; ${ }^{1}$ Hospital Universitario Gregorio Marañón, Madrid, Spain

Background: Patients with inflammatory arthralgia (IA) are considered to be at increased risk for progression to RA. US has shown high sensitivity to detect synovitis compared with physical examination. Thus, US is recommended to identify subclinical synovitis in patients without clinical signs of inflammation.

Objectives: The objective of our study is to determine the frequency and pattern of US detected inflammatory findings in patients with IA and investigate factors contributing to predict these findings.

Methods: An US clinic is scheduled in an academic center running three days every week. A retrospective analysis of our US unit cohort during a period of 6 months was undertaken. Patients with IA and no previous diagnosis of inflammatory arthropathies were included for analysis. Inclusion criteria of IA definition included: severe symptoms presenting in the morning, duration of morning stiffness $\geq 60 \mathrm{~min}$, symptoms predominantly located in MCP joints and abscense of clinically detected synovitis by the referral rheumatologist. The following routinely collected variables were included in the analysis: demographics, clinical features and laboratory tests. Patients underwent bilateral US examination in GS and PD mode of hands and/or feet according to the European League Against Rheumatism (EULAR) guidelines. The presence of synovitis, tenosynovitis and enthesitis was assessed on a semi quantitative scale (0-3) for Grey Scale(GS)/Powe Doppler(PD) or using enthesitis OMERACT definition, respectively. Patients were stratified in two groups based on the presence of US inflammatory findings (synovitis, tenosynovitis or enthesitis with PD signal). First, differences between groups were tested using chi-squared and Student-t tests in the univariate analysis. Second, multivariate logistic regression models were employed to investigate the association between possible predictive factors of US detected inflammatory findings.

Results: A total of 57 patients were included in the analysis. Mean age was $55.8 \pm 15.2$ years, $41(71.9 \%)$ were females, and mean symptoms duration was $11.4 \pm 10.4$ months (Table 1). A total of $42(73.7 \%)$ patients presented with a polyarticular arthralgia pattern. US inflammatory findings were present in 20 (35.1\%) patients $(26.3 \%$ PD synovitis, $21.1 \%$ PD tenosynovitis and $3.5 \%$ PD enthesitis). Hands were most commonly involved with PD synovitis at wrists in $19.3 \%$ and at MCP in $12.3 \%$ of patients (Table 2 ). For PD tenosynovitis, the flexor MCP 2-5 (5.3\%) and compartment IV tenosynovitis (1.8\%) were the most frequent affected locations. Only two patients had PD enthesitis at feet and 6 $(10.5 \%)$ had erosions in hands or feet at baseline examination. In the univariate analysis, the higher ESR values and the shorter time from symptoms onset were significantly associated with US detected inflammatory findings $(p=0.044$ and 0.049 , respectively). In the multivariate analysis, only $E S R$ values ( $O R=1,04$ $95 \% \mathrm{Cl} 1,002-1,078$ ), remained significantly associated with the presence of US inflammatory findings (Table 3 ). 
Table 3. Independent predictors of US detected inflammatory findings

\begin{tabular}{lllll}
\hline & $\mathrm{p}$ & Odds ratio & \multicolumn{2}{c}{$95 \%$ C.I. } \\
\hline & & & Lower & Upper \\
\hline ESR (mm/h) & 0.039 & 1.04 & 1.002 & 1.078 \\
Time (months) from symptoms onset & 0.1 & 0.924 & 0.841 & 1.015 \\
\hline
\end{tabular}

\begin{tabular}{|c|c|c|c|c|c|}
\hline & & $\begin{array}{l}\text { Total } \\
n=57\end{array}$ & $\begin{array}{l}\text { US inflammaterx } \\
\text { findings. } \\
n=20\end{array}$ & $\begin{array}{c}\text { NouULS inflammatory } \\
\text { findings } \\
n=37\end{array}$ & $\mathbf{p}$ \\
\hline Age & & $55.8 \pm 15.2$ & $53.9 \pm 14.5$ & $59.5 \pm 16.2$ & 0.2 \\
\hline Sex & Eepoule & $41(71.9 \%)$ & $13(65 \%)$ & $28(75.7 \%)$ & 0.3 \\
\hline \multirow{3}{*}{$\begin{array}{l}\text { Smoking } \\
n=52\end{array}$} & Non smelecr & $27(47.4 \%)$ & $10(55.6 \%)$ & $17(50 \%)$ & \multirow{3}{*}{0.8} \\
\hline & Semolker & $20(35.1 \%)$ & $6(33.6 \%)$ & $14(41.2 \%)$ & \\
\hline & Eerrear & $5(8.8 \%)$ & $2(11.1 \%)$ & $3(8.8 \%)$ & \\
\hline \multirow{3}{*}{ Extensisa } & Mlonoarticulas & $7(12.3 \%)$ & $3(15 \%)$ & $4(10.8 \%)$ & \multirow{3}{*}{0.9} \\
\hline & Olierearticular & $8(14 \%)$ & $5(25 \%)$ & $3(8.1 \%)$ & \\
\hline & Belvarticular & $42(73.7 \%)$ & $12(60 \%)$ & $30(81.1 \%)$ & \\
\hline \multicolumn{2}{|c|}{$\begin{array}{l}\text { Time (months) } \\
\text { from symptoms onset }\end{array}$} & $11.4 \pm 10.4$ & $7.3 \pm 6.2$ & $13.5 \pm 11.5$ & 0.049 \\
\hline \multicolumn{2}{|c|}{$\begin{array}{l}\text { from symptoms onset } \\
\text { ESR }(\mathrm{mm} / \mathrm{h})\end{array}$} & $19.1 \pm 21$ & & & 0.044 \\
\hline \multirow{2}{*}{\multicolumn{2}{|c|}{$\begin{array}{l}\mathrm{CRP}(\mathrm{mg} / \mathrm{dL}) \mathrm{n}=47 \\
\mathrm{RF}(\mathrm{dU} / \mathrm{mL}) \mathrm{n}=53\end{array}$}} & $0.6 \pm 1.4$ & $1.1 \pm 1.9$ & $0.4 \pm 0.9$ & 0.15 \\
\hline \multirow{2}{*}{\multicolumn{2}{|c|}{$\begin{array}{l}\mathrm{RF}(\mathrm{IU} / \mathrm{mL}) \mathrm{n}=53 \\
\mathrm{CCP}(\mathrm{IU} / \mathrm{mL})\end{array}$}} & $64.3 \pm 321.6$ & $21 \pm 53.7$ & $88.5 \pm 399.7$ & 0.5 \\
\hline & & $522=2314$ & $1048 \pm 3605$ & $223+1036$ & 02 \\
\hline
\end{tabular}

Conclusion: PD US inflammatory findings are found in 1 over 3 patients with IA being PD synovitis the most common finding, specially at the wrists and MCP joints. Higher ESR values were significantly associated with the presence of US inflammatory findings. Our data highlights how the use of PD US may be useful to detect subclinical synovitis in patients with IA.

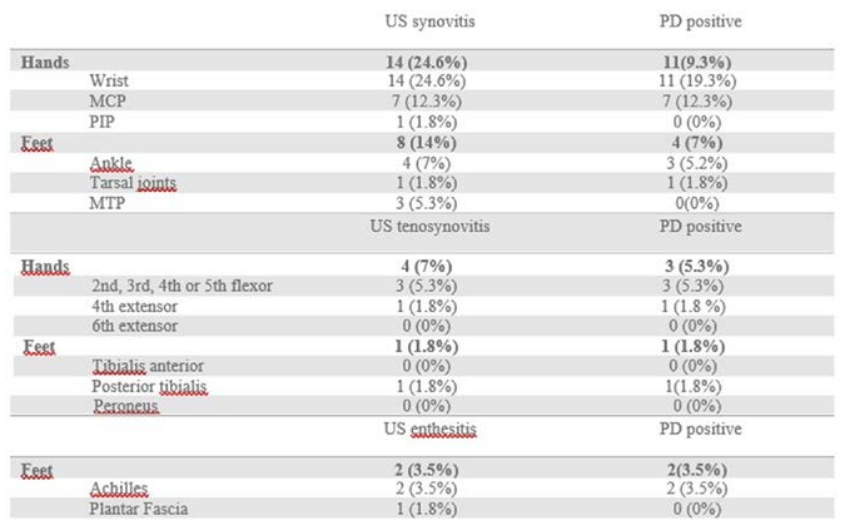

Table 2. US findings of patients with IA

Disclosure of Interests: Katerine López Gloria: None declared, Isabel Castrejon: None declared, Laura Trives Folguera Speakers bureau: ROCHE, Juan Carlos Nieto Speakers bureau: Pfizer, Abbvie, MSD, Novartis, Janssen, Lilly, Nordic Pharma, BMS, Gebro, FAES Farma, Roche, Sanofi, Belén Serrano Benavente: None declared, Julia Martínez-Barrio Consultant of: UCB Pharma, Javier Rivera: None declared, Carlos Gonzalez Consultant of: Gilead, Janssen, Novartis,., Speakers bureau: Abbvie, Celgene, Gilead, Janssen, Novartis, Pfizer, Roche, Indalecio Monteagudo: None declared, Jose-Maria Alvaro-Gracia Grant/research support from: Abbvie, Elli-Lilly, MSD, Novartis, Pfizer, Consultant of: Abbvie, BMS, Janssen-Cilag, Elli-Lilly, MSD, Novartis, Pfizer, Sanofi, Tigenix, Roche, UCB, Paid instructor for: ElliLilly, Pfizer, Roche, Speakers bureau: Abbvie, BMS, Janssen-Cilag, Elli-Lilly, Gedeon Richter, MSD, Novartis, Pfizer, Sanofi, Tigenix, Roche, UCB, Juan Molina Collada: None declared

DOI: 10.1136/annrheumdis-2020-eular.6332

\section{AB0206 $\quad$ CIRCULATING CENTROMERE PROTEIN F AUTOANTIBODIES FOR PREDICTING CLINICAL RESPONSE TO INFLIXIMAB IN RHEUMATOID ARTHRITIS}

L. Lourido $^{1,2}$, C. Ruiz-Romero ${ }^{1,3}$, F. Picchi ${ }^{1}$, N. Diz-Rosales ${ }^{1}$, S. VilaboaGalán ${ }^{1}$, C. Fernández-López ${ }^{1}$, J. A. Pinto Tasende ${ }^{1}$, E. Perez-Pampin ${ }^{4}$, C. Regueiro Expósito ${ }^{4}$, A. Mera Varela ${ }^{4}$, A. Gonzalez ${ }^{4}$, K. Hambardzumyan ${ }^{5}$, S. Saevarsdottir ${ }^{5}$, P. Nilsson ${ }^{6}$, F. J. Blanco ${ }^{1,2} .^{1}$ Grupo de Investigación de Reumatología (GIR), Instituto de Investigación Biomédica de A Coruña (INIBIC), Complexo Hospitalario Universitario de A Coruña (CHUAC), Sergas. Universidade da Coruña (UDC). As Xubias, ${ }^{15006}$. A Coruña, Spain., A Coruña, Spain; ${ }^{2}$ RIER-RED de Inflamación y Enfermedades
Reumáticas, Spain, Madrid, Spain; ${ }^{3}$ CIBER-BBN Instituto de Salud Carlos III, Spain, Madrid, Spain; ${ }^{4}$ Laboratorio Investigacion ${ }^{10}$ and Rheumatology Unit, Instituto de Investigacion Sanitaria-Hospital Clinico Universitario de Santiago, Santiago de Compostela, Spain, Santiago de Compostela, Spain; ${ }^{5}$ Unit of Rheumatology, Department of Medicine, Karolinska Institutet and Rheumatology Clinic, Karolinska University Hospital, Stockholm, Sweden, Stockholm, Sweden; ${ }^{6}$ Division of Affinity Proteomics, Department of Protein Science, KTH Royal Institute of Technology, SciLifeLab, Stockholm, Sweden, Stockholm, Sweden

Background: One third of patients with rheumatoid arthritis (RA) respond poorly to TNF inhibitors and related studies are inconsistent in predictive biomarkers. The identification of biomarkers that predict the treatment response prior to drug exposure is a current priority on the RA field. ACPA and RF are ubiquitously tested in RA patients, but other autoantibodies exist and may provide additional information on RA treatment response.

Objectives: This study aimed to identify circulating autoantibodies for predicting response to infliximab (IFX) in RA.

Methods: We profiled the autoantibody repertoire of baseline sera from 155 biologic naïve RA patients treated with IFX. The sera were provided by three independent clinical sources and distributed in one exploratory cohort $(\mathrm{N}=20)$ collected from Hospital Clínico Universitario of Santiago de Compostela (Spain), one replication cohort $(\mathrm{N}=61)$ collected from Hospital Universitario de A Coruña (Spain) and samples from the Swedish Farmacotherapy (SWEFOT) trial (Sweden) $(\mathrm{N}=74)$ for clinical validation. The presence of autoantibodies and their levels in serum were analysed in association with EULAR clinical response at 6 months follow-up: good response $(\mathrm{GR}, \mathrm{N}=56)$, moderate $(\mathrm{MR}, \mathrm{N}=55)$ and non-response ( $N R, N=44)$. A suspension bead array platform built on protein fragments within Human Protein Atlas and selected from an initial untargeted screening using an array containing 42000 antigens was employed to identify the $\lg G$ and $\operatorname{IgA}$ autoantibodies on the exploratory cohort. A replication and validation phases were carried out on the other two serum sample cohorts. Meta-analysis and Receiver Operating Curves were performed in order to assess the clinical relevance of the findings observed.

Results: Meta-analysis revealed that the levels in serum of IgG autoantibodies against Centromere protein F (CENPF) are significantly increased in responders (good responders and moderate responders; $\mathrm{N}=111$ ) to IFX compared to non-responders $(\mathrm{N}=44)(\mathrm{P}=0.018)$. CENP-F is a proliferation-associated and cell cycle-dependent centromere autoantigen that might be involved in the increased or abnormal cell proliferation that occurs during RA process. The combination of the anti-CENPF antibodies with clinical variables (age, sex, DAS28-ESR) resulted in the best model to discriminate the patients that will respond to IFX, showing an AUC of $0.756(95 \% \mathrm{Cl}[0.639$ 0.874], $P=0.001$ ).

Conclusion: High serum levels of IgG anti-CENPF antibodies might be potentially useful to identify RA patients more likely to benefit from IFX

Disclosure of Interests: Lucía Lourido: None declared, Cristina Ruiz-Romero: None declared, flor picchi: None declared, Naomi Diz-Rosales: None declared, Sergio Vilaboa-Galán: None declared, Carlos Fernández-López: None declared, Jose Antonio Pinto Tasende: None declared, Eva Perez-Pampin: None declared, Cristina Regueiro Expósito: None declared, ANTONIO MERA VARELA: None declared, Antonio Gonzalez: None declared, Karen Hambardzumyan: None declared, Saedis Saevarsdottir Employee of: Part-time at deCODE Genetics/Amgen Inc, working on genetic research unrelated to this project, Peter Nilsson: None declared, Francisco J. Blanco Grant/research support from: Sanofi-Aventis, Lilly, Bristol MS, Amgen, Pfizer, Abbvie, TRB Chemedica International, Glaxo SmithKline, Archigen Biotech Limited, Novartis, Nichi-iko pharmaceutical Co, Genentech, Jannsen Research \& Development, UCB Biopharma, Centrexion Theurapeutics, Celgene, Roche, Regeneron Pharmaceuticals Inc, Biohope, Corbus Pharmaceutical, Tedec Meiji Pharma Kiniksa Pharmaceuticals, Ltd, Gilead Sciences Inc, Consultant of: Lilly, Bristol MS, Pfizer

DOI: 10.1136/annrheumdis-2020-eular.4869

\section{AB0207 CLINICAL IMPACT OF ANTI-CARP ANTIBODIES IN RHEUMATOID ARTHRITIS}

M. Markovic ${ }^{1}$, B. Glisic ${ }^{2}$, M. Petronijevic ${ }^{2}{ }^{1}$ Clinical Center of Montenegro, Clinic of Internal Medicine, Rheumatology Department, Podgorica, Montenegro;

${ }^{2}$ Military Medical Academy, Clinic of Rheumatology, Belgrade, Serbia

Background: Antibodies directed against carbamylated proteins (anti-CarP) have been recently introduced for the first time as a new biomarker in rheumatoid arthritis (RA) (1). Their presence is predictive for the development of RA (2). Anti-CarP antibodies are associated with the development of more severe forms of the disease in overall and anti-citrullinated peptide antibodies negative 